\title{
New Validated Signal-averaging-based Electrocardiography Method to Determine His-ventricle Interval
}

\author{
BALÁZS NÉMETH ${ }^{1,2}$, LÓRÁND KELLÉNYI ${ }^{3}$, ISTVÁN PÉTERFI ${ }^{4}$, TAMÁS SIMOR ${ }^{5}$, \\ DIÁNA RUZSA ${ }^{5}$, HOLCZER LŐRINC ${ }^{5}$, ISTVÁN KISS ${ }^{1}$, IVÁN PÉTER ${ }^{2}$ and ZÉNÓ AJTAY ${ }^{2,5}$ \\ ${ }^{1}$ Department of Public Health Medicine, Medical School, University of Pécs, Pécs, Hungary; \\ ${ }^{2}$ Zsigmondy Vilmos SPA Hospital, Harkány, Hungary; \\ ${ }^{3}$ Hungarian Academy of Sciences, Budapest, Hungary; \\ ${ }^{4}$ Department of Obstetrics and Gynecology, Kaposi Mór Teaching Hospital, Kaposvár, Hungary; \\ ${ }^{5}$ Heart Institute, Medical School, University of Pécs, Pécs, Hungary
}

\begin{abstract}
Background/Aim: The signal-averaging (SA) technique is used to record high-resolution electrocardiograms (HRECGs) showing cardiac micropotentials. We aimed to develop a non-invasive signal-averaging-based portable bedside device to determine His-ventricle interval. Patients and Methods: After amplifying the HRECG recordings, signal duration and voltage can be measured up to four decimal precision. To validate our system, comparison of the invasively and non-invasively determined $H V$ intervals has been performed in 20 patients. Results: Our workgroup has developed a system capable of displaying and measuring cardiac micropotentials on storable ECG. Neither related paired-sample T-test $(p=0.263)$ nor Wilcoxon's non-parametric signed ranks test $(p=0.245)$ showed significant deviations of the HV intervals. Furthermore, related paired-sample T-test showed strong correlation (corr $=0.910, p<0.001$ ) between $H V$ intervals determined by electrophysiology (EP) and noninvasive measurements. Conclusion: Our research group managed to assemble and validate an easy to use device capable of determining $H V$ intervals even under ambulatory conditions.
\end{abstract}

According to latest World Health Organization (WHO) reports, cardiovascular (CV) disease is the worldwide leading cause of death (1). With an incidence of 180,000 to 450,000 yearly, sudden cardiac death (SCD) is a major health issue (2). As usual, the incidence of SCD is increasing with age but

Correspondence to: Balázs Németh, MD, Department of Public Health Medicine, Medical School, University of Pécs, Szigeti Str. 12, 7624 Pécs, Hungary. Tel: +36 72536394, Fax: +36 72536395, e-mail: balazs.nemeth@aok.pte.hu

Key Words: Cardiac electrophysiology, high-resolution electrocardiography, risk stratification. the proportion of death considered as SCD is higher in younger patients (3). Evaluating the genetic background of SCD victims, disorders have been found in genes related to cardiac conduction, sympathetic system and atherogenesis (2). Beside classic risk factors like age, sex, smoking, obesity and diabetes, heart rate, QRS duration, QT interval and the onset of early repolarization have been proven as relevant risk factors of SCD (4-8). Along conventional electrocardiogram (ECG) parameters mentioned above, signal-averaging (SA) technique grants unique findings holding relevant information about heart conduction. SA is one of the oldest methods -first applied in 1947- to provide a high-resolution ECG that is capable of showing cardiac micropotentials in a non-invasive way. The SA technique is based on storing and averaging electric potentials of multiple heart circles; by summarizing heartbeats, a high-resolution signal averaged ECG (HRSAECG) recording is created (10). HRSAECGs provide several findings of clinical interest. One of these is the ventricular late potential (VLP). VLPs are micropotentials shown by HRECGs, found in the terminal part of the QRS complex. VLPs have been used in risk stratification of several $\mathrm{CV}$ diseases, principally in life-threatening ventricular arrhythmias and SCD (11-13). Furthermore, the onset of VLPs indicates a conduction delay most commonly caused by myocardial injury. Moreover, VLPs can be used to reveal high-risk patients suffering from Brugada syndrome (BS) (14) and arrhythmogenic right ventricular cardiomyopathy (ARVC) $(15,16)$. Eliminating VLPs, using radiofrequency, catheter ablation has been proven a successful method for reducing arrhythmia recurrence in cases of scar related ventricular tachycardia (17).

According to a prospective multicenter trial involving nearly 4,000 patients, duration of terminal portion of QRS recorded by SAECG can predict arrhythmic death in patients after myocardial infarction (18). Besides detecting VLPs, HRSAECG is capable of recording the electric activity of the 
His bundle. According to latest guidelines, if the HV interval is greater than or equal to 100 milliseconds (ms), pacemaker implantation is advised, even in the case of asymptomatic patients (19). Elongated HV intervals can indicate peripheral conduction disorders. These findings are especially useful in risk assessment if bifascicular block is presented. As reported by a study with a follow-up period of 3 years, progression of bundle branch blocks to complete AV block (AVB) was detected in $24 \%$ of patients with HV intervals $\geq 100 \mathrm{~ms}$. In addition, progression to high-degree atrioventricular block occurred more frequently in patients with elongated HV intervals than in patients with HV intervals less than $100 \mathrm{~ms}$ (20). Moreover, Martí-Almor et al. found higher risk of AVB in patients with $\mathrm{HV}$ intervals exceeding $64 \mathrm{~ms}$ (21). According to a follow-up study involving 227 patients, HV interval can predict "pacemaker need" with a sensitivity of $74 \%$ and a specificity of $78 \%$ (22). These studies provided evidence that HV interval is a useful predictor of AVB, particularly in patients with bifascicular block. The onset of VLPs shown by a non-invasive method can provide valuable knowledge to the physician to facilitate individual risk assessment. In addition, in some cases, HV intervals determined non-invasively can support pacemaker indication.

\section{Patients and Methods}

Our workgroup has developed a new bedside device capable of detecting VLPs and showing the electric activity of His bundle on a HR-SAECG. The leading idea of our system is based on the SAECG recording device developed by Lóránd Kellényi et al. in 1977 (23). These former findings gave a solid foundation and raised goals achieved by this novel system (24).

Our device uses three "EURO standard" surface electrodes to obtain a proper ECG signal. Two active electrodes need to be placed parallel to the ventricular septum. The third, so called "active ground" electrode, is connected to the mutual ground through a 5 kohm electric resistance. Giving a 100 times amplified reverse period, common-mode signal trough a $1 \mathrm{kohm}$ resistance to the active ground will greatly reduce $50 \mathrm{~Hz}$ noises.

Body surface electrodes are connected to the transmitter unit. The transmitter is equipped with a $\lambda / 4$ helical antenna capable of sending radio frequency (RF) signals at $433 \mathrm{MHz}$ in a range of 25 meters. The antenna is connected to a metal rack that contains the analog/digital (A/D) converter chip and current circuits responsible for converting electric potentials of the heart to transpondable signals. Sample sending is performed at $4,500 \mathrm{~Hz},+/-22 \% \mathrm{FM}$.

The receiver unit is also fitted with a $\lambda / 4$ helical antenna and contains a RF receiver chip. The encoded signal travels from the receiver chip through several filters and amplifiers to the digital/analog (D/A) converter that is connected to a 9-poled lineal Thomson filter. The analog signals are fed to a 16-bit A/D converter (National Instruments USB 6009), which is used to pass the digitalized signals to the computer through USB connection. Energy supply of the receiver is unbound through the USB cable. To ensure patient safety, the evaluation system is completely cut-off.

The electric activity of the heart wirelessly transferred to the computer is signal-averaged and evaluated by the "ECG
Table I. Clinical characteristics of patients.

\begin{tabular}{lc}
\hline No. of patients & 20 \\
Age (years) & $48 \pm 16$ \\
Gender M/F & $9 / 11$ \\
Hypertension n (\%) & $11(55 \%)$ \\
Diabetes n (\%) & $6(30 \%)$ \\
Hyperlipidemia n (\%) & $4(20 \%)$ \\
Coronary artery bypass grafting surgery & \\
$\mathrm{n}(\%)$ & $1(5 \%)$ \\
Smoking n $(\%)$ & $4(20 \%)$ \\
\hline
\end{tabular}

Micropotential Analyzer" software developed by István Péterfi (25). A modified version of this software was earlier used to register and analyze fetal ECG during the third trimester of pregnancy (25). The received ECG has a bandwidth of $0.25 \mathrm{~Hz}$ to $1,500 \mathrm{~Hz}$. Sampling can be performed from $500 \mathrm{~Hz}$ to $10,000 \mathrm{~Hz}$. Obtaining low noise electric potentials repeatedly is essential to get a proper recording. To pass this requirement, our device is fitted with peak and amplitude trigger. The peak trigger recognizes the peak of the $\mathrm{R}$ wave. Using the amplitude trigger mode, which triggers on the preset amplitude of the $\mathrm{R}$ wave, respiratory arrhythmia can be by-passed. Ectopic beats (e.g. ventricular extrasystole, noisy beats) will be rejected by the software; in addition, insufficient signals can be excluded manually from the memory. HRECG is presented real-time while recording of heart circles is performed. After all, some external factors (e.g. temperature, abdominal wall thickness, electrode conduction issues, etc.) can alter the signals obtained from the heart. To emerge this, our evaluating system has been fitted with adjustable high-pass, band-pass and low-pass filters. Furthermore, using a special cure evaluating algorithm, peaks are identified beat by beat, thus allowing the precise detection of micropotentials. After proper amplification (up to 10,000 times), filter setting and peak recognizing measurements (width in $\mathrm{ms}$, height in $\mathrm{uV}$ ) can be performed manually. Our device is capable of performing four decimal precision measurements of duration and voltage of a selected structure. Furthermore, digital filtering can be used to enhance the quality of the HRECG. For later investigations and comparison, the acquired HR-SAECG is saved to the computer. In addition, the patient's heart rate profile can be displayed on a cardiogram.

Our aim was not just to assemble but to validate a device capable of bedside recording and measuring cardiac micropotentials. To achieve this goal, 20 patients who underwent electrophysiology (EP) study have been recruited: mean age $48 \pm 16$ years, 9 males and 11 females. The clinical characteristics of the involved patients are shown in Table I.

Nine patients were diagnosed with AV nodal re-entry tachycardia and nine with paroxysmal supraventricular tachycardia. In case of the two remaining patients, EP study was indicated by WolffParkinson-White syndrome.

To compare HV intervals provided by EP study and our noninvasive device, the following procedure was performed on every patient. During EP study -after cardiac mapping (EnSite ${ }^{\mathrm{TM}} \mathrm{NavX}^{\mathrm{TM}}$; St. Jude Medical, St. Paul, MN, USA)- the catheter (IBI Therapy ${ }^{\text {тм }}$

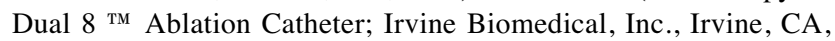
USA) was positioned to record the electric potentials of His bundle 


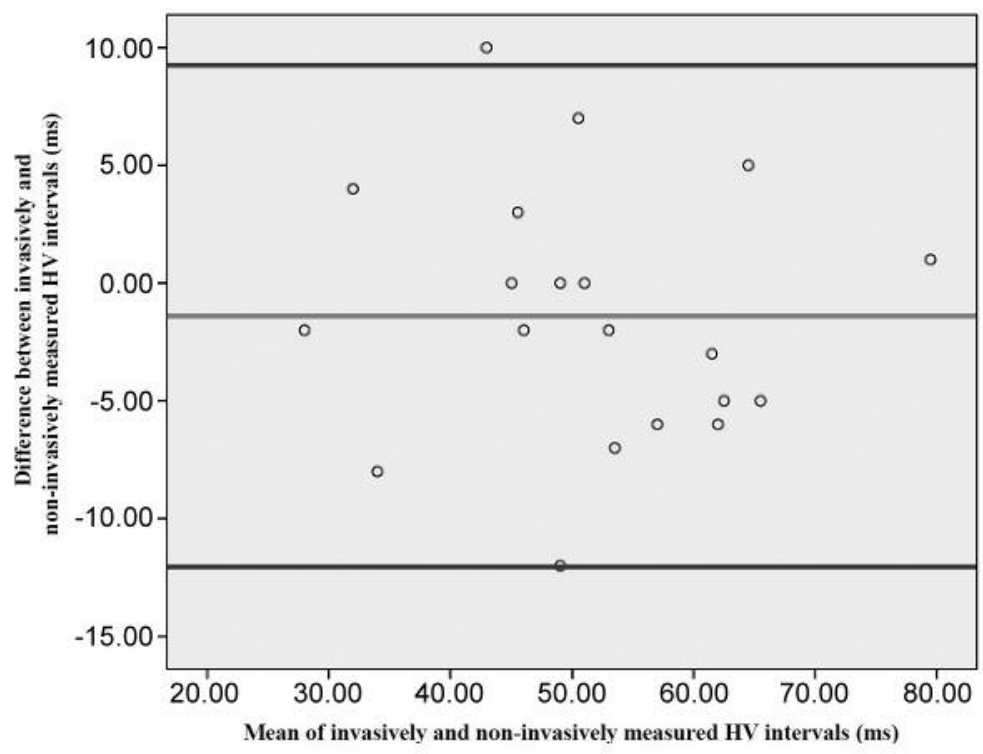

Figure 1. Bland-Altman plot of invasively and non-invasively measured HV intervals.

for later investigation. Within 4 hours using our device, the electric potentials of His bundle has been detected in a non-invasive way in the same patient; HRECG was saved for evaluation. In these 4 hours, conductions effecting medications were not administered to the patients. HV intervals provided by EP and non-invasive study have been determined by two different investigators. Paired-sample T-test and Wilcoxon's non-parametric signed ranks test have been used to analyze inequality between HV intervals provided by EP study and our non-invasive device. Our study was approved by the local ethics committee, permission No.: 5920, in accordance with the 2008 Helsinki declaration. Informed written consent was obtained from every patient.

\section{Results}

The statistic comparison of the invasively and non-invasively determined HV intervals (Figure 1) has been performed with IBM SPSS Statistic, Version 22 (IBM Corp, Armonk, NY, USA) software. Neither related paired-sample T-test $(p=0.263)$ nor Wilcoxon's non-parametric signed ranks test $(p=0.245)$ showed significant deviations of the HV intervals. Furthermore, paired-sample T-test showed strong correlation (corr $=0.910$, $p<0.001$ ) between HV intervals measured by EP and our device. In addition, Bland-Altman plot (Figure 1) showed no significant difference between the HV intervals -either short or long- determined invasively and non-invasively $(p=0.666)$.

A digital filtered SAECG of a healthy individual provided by our system is shown on Figure 2. After averaging 250 beats, the electric activity of the atrium and the QRS complex are shown. Small circles are indicating the deflection of the curve beat by beat presenting peaks nearly on the same location regarding all the 250 averaged hear circles.

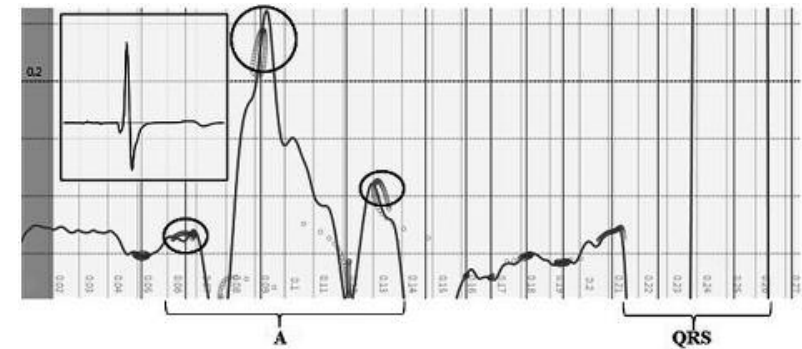

Figure 2. Digital filtered high-resolution electrocardiogram (HRECG) of a 27-year-old male, composed by 250 averaged heart circles. A: electric activity of the atrium, QRS: amplified part of the QRS complex. Note: The three characteristic electric components of the atrium are indicated with a ring.

After applying proper amplification, the electric potential of the His bundle is presented and the HV interval can be measured (Figure 3). Once again, the peak-recognizing algorithm is applied. This technique is particularly useful to identify the electric activity of the His bundle by clarifying its position on the HRECG.

Averaging 300 beats is sufficient to detect VLPs. Figure 4 shows two VLPs. The recording was performed on an 85year-old male patient gone through two diagnosed myocardial infarctions. The recording was performed with the following settings: high-pass filter $=40 \mathrm{~Hz}$, low-pass filter $=250 \mathrm{~Hz}$, sampling rate $=2,000 \mathrm{~Hz}$. To reduce noise, digital filtering was applied; unfiltered HRECG is also shown. 


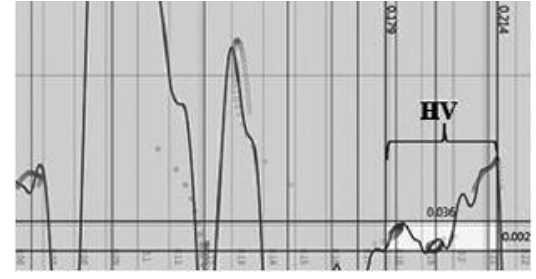

Figure 3. Digital filtered high-resolution electrocardiogram (HRECG) of a 27-year-old male, amplified to reveal the electric potential of the His bundle by using peak recognition algorithm ( $H V$ interval $36 \mathrm{~ms}$ ).

\section{Discussion}

Nowadays, modern EP centers are available for the diagnosis and treatment of particular arrhythmias. However, these interventions are invasive, require expensive equipment and respectable funds for maintenance. Some information, such as His-ventricle interval, provided by the invasive EP study, can be obtained by non-invasive methods like the SA technique.

In patients presented with syncope, determining $\mathrm{HV}$ interval is a substantial pivot of PM indication $(26,27)$. In the cases of patients with bifascicular block, HV interval is considered to be a useful predictor of $\operatorname{AVB}(20,21,22,26)$. Using our validated device, the information granted by $\mathrm{HV}$ intervals can be obtained non-invasively under ambulatory conditions at a low-cost. The system provided by our workgroup is appropriate to follow patients with bifascicular block by determining $\mathrm{HV}$ interval without an invasive intervention. Moreover, a bedside non-invasive method for measuring HV intervals could be a great tool to support pacemaker indication.

As mentioned above, the SA method has been used worldwide to assess cardiovascular risk.

Although the use of VLPs in CV risk prediction is controversial, several studies found connections between the presences of VLPs and the onset of SCD $(11-13,19,26)$. VLPs can be useful in risk stratification of patients suffering from Brugada syndrome (14) or arrhythmogenic right ventricular dysplasia (ARVD) $(15,16)$. VLPs can provide unique information about myocardial state (28) but, because of their low positive predictive value, VLPs must be used along with classic CV risk factors. Our device is fitted with adjustable high-pass and low-pass filters to reduce noise to acquire a sufficient recording in the cases of fragmented or delayed conductions, which remain hidden for devices with preset filters. Furthermore, digital filtering is available to improve the quality of registration. VLPs shown by our noninvasive bedside method can provide valuable knowledge to the physician to facilitate individual risk assessment (e.g. Brugada syndrome, ARVD). Apart the well-known limitations of every conduction-based method, in some cases of structural

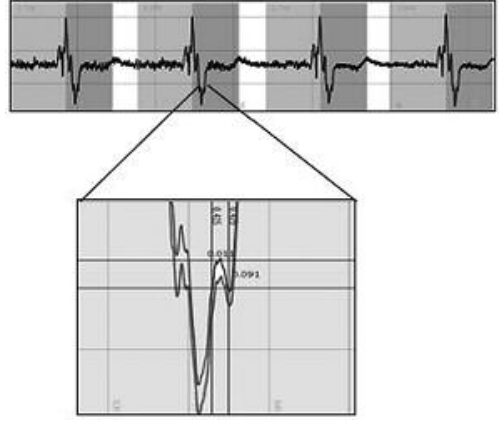

Figure 4. Unfiltered and digital filtered high-resolution electrocardiogram (HRECG) of a 85-year-old male patient-gone through two diagnosed myocardial infarctions- showing two ventricular late potentials (VLPS) in the terminal $40 \mathrm{~ms}$ of the $Q R S$.

heart diseases (e.g. ventricular hypertrophy), the proper placement of electrodes can be challenging.

\section{Conclusion}

Our workgroup aimed to revitalize the SA method by developing and validating an easy to use bedside device capable of determining HV intervals and onset of VLPs to aid the ranks of current risk assessment tools.

\section{Conflicts of Interest}

The Authors declare that there is no conflict of interest regarding the publication of this paper.

\section{Acknowledgements}

The Authors express their special thanks to all the nurses of the Electrophysiology Department for their invaluable help during measurements. The present scientific contribution is dedicated to the 650th anniversary of the foundation of the University of Pécs, Hungary.

\section{References}

1 WHO: Global status report on noncommunicable diseases 2014. 2014; 9-11. Downloaded on 2016.08.10. from: http://apps.who. int/iris/bitstream/10665/148114/1/9789241564854_eng.pdf

2 Deo R and Albert CM: Epidemiology and genetics of sudden cardiac death. Circulation 125(4): 620-637, 2012. (PubMed: 22294707)

3 Krahn AD, Connolly SJ, Roberts RS, Gent M and ATMA Investigators: Diminishing proportional risk of sudden death with advancing age: implications for prevention of sudden death. Am Heart J 147(5): 837-840, 2004. (PubMed: 15131539)

4 Cupples LA, Gagnon DR and Kannel WB: Long- and short-term risk of sudden coronary death. Circulation 85: I11-I18, 1992. (PubMed: 1370216) 
5 Morin DP, Oikarinen L, Viitasalo M, Toivonen L, Nieminen MS Kjeldsen SE, Dahlöf B, John M, Devereux RB and Okin PM: QRS duration predicts sudden cardiac death in hypertensive patients undergoing intensive medical therapy: the life study. Eur Heart J 30: 2908-2914, 2009. (PubMed: 19687165)

6 Straus SM, Kors JA, De Bruin ML, van der Hooft CS, Hofman A, Heeringa J, Deckers JW, Kingma JH, Sturkenboom MC, Stricker BH and Witteman JC: Prolonged QTc interval and risk of sudden cardiac death in a population of older adults. J Am Coll Cardiol 47: 362-367, 2006. (PubMed: 16412861)

7 Algra A, Tijssen JG, Roelandt JR, Pool J and Lubsen J: QTc prolongation measured by standard 12-lead electrocardiography is an independent risk factor for sudden death due to cardiac arrest. Circulation 83: 1888-1894, 1991. (PubMed: 2040041)

8 Jouven X, Zureik M, Desnos M, Guérot C and Ducimetiére P: Resting heart rate as a predictive risk factor for sudden death in middle-aged men. Cardiovasc Res 50: 373-378, 2001. (PubMed: 11334841)

10 Jarrett RJ and Flowers CN: Signal-averaged electrocardiography: History, techniques, and clinical application. Clin Cardiol 14: 984-994, 1991. (PubMed: 1841024)

11 Santangeli P, Infusino F, Sgueglia GA, Sestito A and Lanza GA: Ventricular late potentials: a critical overview and current applications. J Electrocardiol 41: 318-324, 2008. (PubMed: 18455179)

12 Kuchar DL, Thorburn CW and Sammel NL: Late potentials detected after myocardial infarction: Natural history and prognostic significance. Circulation 74(6): 1280-1289, 1986. (PubMed: 3779914)

13 Seale WL, Gang ES and Peter CT: The use of signal-averaged electrocardiography in predicting patients at high risk for sudden death. Pacing Clin Electrophysiol 13(6): 796-807, 1990 (PubMed: 1695360)

14 Huang Z, Patel C, Li W, Xie Q, Wu R, Zhang L, Tang R, Wan X, Ma Y, Zhen W, Gao L and Yan GX: Role of signal-averaged electrocardiograms in arrhythmic risk stratification of patients with Brugada syndrome: a prospective study. Heart Rhythm 6: 1156-1162, 2009. (PubMed: 19632627)

15 Nasir K, Tandri H, Rutberg J, Tichnell C, Spevak P, Crossan J, Baughman KL, Kasper EK, Tomaselli GF, Berger R and Calkins H: Filtered QRS duration on signal-averaged electrocardiography predicts inducibility of ventricular tachycardia in arrhythmogenic right ventricle dysplasia. Pacing Clin Electrophysiol 26(10): 1955-1960, 2003. (PubMed: 14516335)

16 Kamath GS, Zareba W, Delaney J, Koneru JN, McKenna W, Gear K, Polonsky S, Sherrill D, Bluemke D, Marcus F and Steinberg JS: Value of the signal-averaged electrocardiogram in arrhythmogenic right ventricular cardiomyopathy/dysplasia. Heart Rhythm 8: 256-262, 2011. (PubMed: 20933608)

17 Vergara P, Trevisi N, Ricco A, Petracca F, Baratto F, Cireddu M, Bisceglia C, Maccabelli G and Della Bella P: Late potentials abolition as an additional technique for reduction of arrhythmia recurrence in scar related ventricular tachycardia ablation. J Cardiovasc Electrophysiol 23(6): 621-627, 2012. (PubMed: 22486970)

18 Savard P, Rouleau JL, Ferguson J, Poitras N, Morel P, Davies RF, Stewart DJ, Talajic M, Gardner M, Dupuis R, Lauzon C, Sussex B, Potvin L and Warnica W: Risk stratification after myocardial infarction using signal-averaged electrocardiographic criteria adjusted for sex, age, and myocardial infarction location. Circulation 96(1): 202-213, 1997. (PubMed: 9236435)
19 Tracy CM, Epstein AE, Darbar D, DiMarco JP, Dunbar SB, Estes NA 3rd, Ferguson TB Jr, Hammill SC, Karasik PE, Link MS, Marine JE, Schoenfeld MH, Shanker AJ, Silka MJ, Stevenson LW, Stevenson WG, Varosy PD, Ellenbogen KA, Freedman RA, Gettes LS, Gillinov AM, Gregoratos G, Hayes DL, Page RL, Stevenson LW, Sweeney MO; American College of Cardiology Foundation; American Heart Association Task Force on Practice Guidelines and Heart Rhythm Society: 2012 ACCF/AHA/HRS Focused Update: 2012 ACCF/AHA/HRS Focused Update of the 2008 Guidelines for Device-Based Therapy of Cardiac Rhythm Abnormalities: A Report of the American College of Cardiology Foundation/American Heart Association Task Force on Practice Guidelines and the Heart Rhythm Society. Circulation 126(14): 1784-1800, 2012. (PubMed: 22965336)

20 Fisch GR, Zipes DP and Fisch C: Bundle branch block and sudden death. Prog Cardiovasc Dis 23(3): 187-224, 1980. (PubMed: 7001541)

21 Martí-Almora J, Cladellasa M, Bazána V, Delclós J, Altaba C, Guijo MA, Vila J, Mojal S and Bruguera J: Novel predictors of progression of atrioventricular block in patients with chronic bifascicular block. Rev Esp Cardiol 63(4): 400-408, 2010. (PubMed: 20334805)

22 Scheinman MM, Peters RW, Suavé MJ, Desai J, Abbott JA, Cogan J, Wohl B and Williams K: Value of the H-Q interval in patients with bundle branch block and the role of prophylactic permanent pacing. Am J Cardiol 50(6): 1316-1322, 1982. (PubMed: 7148708)

23 Horváth M, Kellényi L and Böszörményi E: Arrhythmia analysis by Hungarian produced equipment. Mérés és Automatika 10: 372-376, 1977.

24 Rostás L, Gesztesi T, Józan M and Kellényi L: Testfelületi elvezetéssel regisztrált kamrai (LATE) késốipotenciál myocardium infarctusban. Orv Hetil 129(21): 1097-1103, 1988.

25 Peterfi I, Kellenyi L and Szilagyi A: Noninvasive recording of true-to-form fetal ecg during the third trimester of pregnancy. Obstet Gynecol Int 2014: 5 pages, 2014. (PubMed: 25374606)

26 Breithardt G, Cain ME, el-Sherif N, Flowers NC, Hombach V, Janse M, Simson MB and Steinbeck G: Standards for analysis of ventricular late potentials using high-resolution or signalaveraged electrocardiography. A statement by a Task Force Committee of the European Society of Cardiology, the American Heart Association, and the American College of Cardiology. Circulation 83(4): 1481-1488, 1991. (PubMed: 2013173)

27 Vardas PE, Auricchio A, Blanc JJ, Daubert JC, Drexler H, Ector H, Gasparini M, Linde C, Morgado FB, Oto A, Sutton R, TruszGluza M; European Society of Cardiology and European Heart Rhythm Association: Guidelines for cardiac pacing and cardiac resynchronization therapy. Europace 28(18): 959-998, 2007. (PubMed: 17726042)

28 Benchimol Barbosa PR, Sousa MO, Barbosa EC, Bomfim AS, Ginefra P and Nadal J: Analysis of the prevalence of ventricular late potentials in the late phase of myocardial infarction based on the site of infarction. Arq Bras Cardiol 78(4): 352-363, 2002. (PubMed: 12011951)
Received August 28, 2016

Revised September 8, 2016

Accepted September 9, 2016 